\title{
Effect of fasting during Ramadan on fetal Doppler indices and amniotic fluid volume
}

\author{
Mostafa Abd Elbar, Ahmed M. Abdelhak, Ahmed N Askalany
}

Department of Obstetrics and Gynecology, Kasr Aini Hospital, Cairo University, Cairo, Egypt

\begin{abstract}
Aim of work: To assess the effect of fasting for a whole month during Ramadan on the fetal Doppler indices and amniotic fluid index.

Patients and Methods: The study involved 240 healthy women in the third trimester of a normal singleton pregnancy. The umbilical artery resistance index (RI) and middle cerebral artery (MCA) pulsatility index (PI) and the amniotic fluid index were measured at the beginning of Ramadan and at the end of the month. Of the included women, 157 (65.4\%) chose to fast (Group 1) and 83 (34.6\%) were not fasting (Group 2).

Results: On reassessment, 9 participants were lost to follow up, 2 women developed hypertension and another woman had preterm delivery. Thus, results at the end of Ramadan were presented for 228 women; 152 in the fasting and 76 in the non-fasting group. On initial assessment, there was no significant difference between fasting and non-fasting women regarding umbilical artery RI $(p=0.645)$, MCA PI $(p=0.581)$ and AMF $(p=0.070)$. During re-assessment at the end of Ramadan, there was no significant difference between the two groups regarding umbilical artery RI $(p=0.519)$, MCA PI $(p=0.383)$ and AMF $(p=0.339)$. At the end of Ramadan, there was a statistically significant decrease of Doppler indices and AFI. However, all values were within the clinically accepted range.

Conclusion: Maternal fasting during Ramadan does not adversely affects fetal condition based on finding of normal Doppler indices and amniotic fluid index, provided woman is young and healthy.
\end{abstract}

Key Words: Fasting during Ramadan, fetal Doppler.

Received: 01 May 2018, Accepted: 28 May 2018

Corresponding Author: Ahmed M. Abdelhak, M.D., Department of Obstetrics and Gynecology, Kasr Aini Hospital, Cairo University, Cairo, Egypt, Tel.: 01222259009, E-mail: ah.abdelhak73@gmail.com

ISSN: 2090-7265, August 2018, Vol.8, No.3

\section{INTRODUCTION}

Ramadan is a lunar month during which Muslims abstain from food and drink from Dawn to Sunset. Pregnancy is a cause to exempt woman from fasting, if she feels danger to herself or her fetus. Fasting during Ramadan is considered short-term fasting (about 12-15 hours). Fasting for $<15$ hours is considered metabolically similar to physiological overnight fast in healthy pregnant woman ${ }^{[1]}$.

It was reported that women have a significant fall in glucose, insulin, lactate, and carnitine levels in addition to an increase in triglyceride concentrations as a result of fasting ${ }^{[2]}$. These changes are related to the gestational age; glucose values were significantly lower and free fatty acids were significantly higher in late pregnancy than in early pregnancy ${ }^{[3]}$, Gin et al. ${ }^{[4]}$ observed mild maternal and fetal ketosis during the third trimester and in the newborn infant in the early neonatal period.

Animal studies assessed the metabolic effects of fasting during pregnancy. Pregnancy up-regulated leptin mRNA expression in adipose tissue in ewes with adequate feeding, while nutrition at half maintenance impaired this response $\mathrm{e}^{[5]}$
It was found that plasma leptin and insulin concentrations were strongly correlated ${ }^{[5,6]}$. Also, undernourished ewes lack the normal increase of hepatic expression of insulinlike growth factor-1 (IGF-1) mRNA during pregnancy. These low levels of plasma concentrations of insulin and IGF-1 were explained by higher endocrine uptake by the target tissues ${ }^{[5]}$. Another study on cows during late pregnancy reported comparable hepatic expression of growth hormone receptor-1A (GHR-1A) mRNA as in nonpregnant cows ${ }^{[7]}$.

As was observed in humans, food restriction during pregnancy depends on gestational period. Brecchia et al[8] examined the effect of the food restriction on maternal leptin plasma concentrations and productive performance of rabbit does and their litters. They showed that rabbits quickly recover weight loss due to food restriction in early pregnancy, while restriction in the last third of pregnancy produced a reduction of productive performance and impairment of milk production.

Earlier studies in humans suggested that fasting during Ramadan produced no effect on Apgar scores, birth weight, timing of delivery, or newborns' health ${ }^{[9-11]}$. Other studies reported complaints as giddiness, nausea and 
vomiting $^{[12]}$. Recent survey in Pakistan reported that hunger, thirst and weakness were the most frequent side effects during fasting, while severe vomiting and taking medication were the reasons that nullify fasting ${ }^{[13]}$.

Fasting in Ramadan is one of the five fundamental pillars of Islam; with pregnancy as one of the possible reasons of exemption. Doctors and health workers are frequently counseled regarding fasting during pregnancy. They should be aware of religious obligations as well as having rigorous medical evidence about the effects of fasting and possible harm to the mother or her fetus, i.e. they have to provide an informed decision. Most of the previous studies assessed the effect of abstaining food rather than drinks. The effect of short-term dehydration during fasting on fetal behavior was not adequately studied. Doppler studies afford an appropriate assessment of fetal dehydration during pregnancy. Thus, in the current study we tried to assess the effect of fasting for a whole month during Ramadan on the fetal Doppler indices and amniotic fluid index.

\section{PATIENTS AND METHODS}

The study involved 240 women in the third trimester of a singleton pregnancy. They were assessed at the beginning and the end of Ramadan month in the years $2010(\mathrm{n}=82)$, $2011(n=74)$ and $2012(n=84)$. All women had no medical disorders that may affect fetal Doppler indices or amount of liquor, as hypertension, diabetes, growth retardation and systemic lupus erythematosus.

Initially, umbilical artery resistance index (RI) and middle cerebral artery (MCA) pulsatility index (PI) were normal in all women and there was no case of oligohydramnios. All women had no risk factors that can prohibit fasting. The umbilical RI, MCA PI and the amniotic fluid index were measured at the beginning of Ramadan month and again at the end of the month. Of these women, 157 (65.4\%) chose to fast (Group 1) and 83 (34.6\%) were not fasting (Group 2). Fasting hours were between 14 and 15 hours.

The study was approved by the Ethical Committee of the Department of Obstetrics and Gynecology, Cairo University. Each participant provided a written informed consent. Inclusion criteria were healthy pregnant women with a singleton pregnancy. Gestational age was confirmed by sure dates of last menstrual period and/ or documented first trimester ultrasound between 11 and 14 weeks. Exclusion criteria included - in addition to medical disorders - evidence of placental insufficiency, nonreactive non-stress test, diminished fetal movements and intrauterine growth restriction.

Initial assessment was done on first day of Ramadan including complete medical history taking and general physical and obstetric examination. Then, all participants were submitted to ultrasound and Doppler blood flow velocity waveform examination using a device combining B-mode-imaging and a bidirectional pulsed color Doppler technique (GE Voluson 730).

The blood flow velocity waveform was studied in the fetal umbilical artery at a free loop of the cord near its attachment to the umbilicus and in the middle cerebral artery. All examinations were conducted using a convex 3.5 $\mathrm{MHz}$ probe with the patient in the recumbent position. Resistance index was measured in umbilical artery and pulsatility index was measured in the MCA.

Amniotic fluid index (AFI) was measured according to Phelan et al. ${ }^{[14]}$. The amniotic cavity is divided into 4 quadrants using the maternal linea nigra as the midline. The deepest vertical pocket in each quadrant is determined and measured. AFI is the sum of the 4 deep pockets. An $\mathrm{AFI} \leq 5 \mathrm{~cm}$ was considered oligohydramnios. Assessment was repeated at the end of Ramadan (last 3 days) including physical examination in addition to Doppler indices and AFI.

Statistical analysis was performed using SPSS version 20.0 (SPSS, Chicago, IL, USA). Continuous variables were compared using the t-test. All statistical tests were two-tailed. A $p$ value $<0.05$ is considered significant.

\section{RESULTS}

On reassessment 9 participants were lost to follow up, 2 women developed hypertension and another woman had preterm delivery. Thus, results at the end of Ramadan were presented for 228 women; 152 in the fasting and 76 in the non-fasting group.

Table 1: Demographic and Clinical characteristics of the two studied groups

\begin{tabular}{lccc}
\hline & $\begin{array}{c}\text { Fasting Group } \\
(\mathrm{n}=157)\end{array}$ & $\begin{array}{c}\text { Not fasting Group } \\
(\mathrm{n}=83)\end{array}$ & $p$ value \\
\hline Age (years) & $25.5 \pm 3.6$ & $24.8 \pm 3.3$ & 0.117 \\
Gestational age (week) & $31.6 \pm 1.7$ & $31.5 \pm 1.7$ & 0.638 \\
Parity, median (range) & $2(1-3)$ & $1(1-3)$ & 0.482 \\
\hline
\end{tabular}


Table 2: Doppler indices and amniotic fluid index at the beginning and end of Ramadan of the two studied groups

\begin{tabular}{lccc}
\hline & $\begin{array}{c}\text { Fasting Group } \\
(\mathrm{n}=152)\end{array}$ & $\begin{array}{c}\text { Not fasting Group } \\
(\mathrm{n}=76)\end{array}$ & $p$ value \\
\hline Umbilical Artery RI & & & $0.64 \pm .02$ \\
Ramadan Start & $0.64 \pm 0.01$ & $0.61 \pm 0.02$ & 0.645 \\
Ramadan End* & $0.62 \pm 0.02$ & & 0.519 \\
Middle cerebral Artery PI & & $1.88 \pm 0.10$ & 0.581 \\
Ramadan Start & $1.88 \pm 0.10$ & $1.54 \pm 0.20$ & 0.383 \\
Ramadan End* & $1.51 \pm 0.20$ & & 0.070 \\
Amniotic fluid Index & & $13.2 \pm 1.0$ & 0.339 \\
Ramadan Start & $13.4 \pm 1.0$ & $12.0 \pm 0.9$ & \\
Ramadan End* & $12.1 \pm 0.9$ & & \\
\hline
\end{tabular}

Data as mean \pm SD

Included women were relatively young; the mean age was around 25 years, with median parity of 1 to 2 . The two groups were of comparable age, parity and gestational age at inclusion (Table 1). On initial assessment, there was no significant difference between fasting and non-fasting women regarding umbilical artery RI $(\mathrm{p}=0.645)$, MCA PI $(p=0.581)$ and AMF $(p=0.070)$. During re-assessment at the end of Ramadan, there was no significant difference between the two groups regarding umbilical artery $\mathrm{RI}(p=0.519)$, MCA PI $(p=0.383)$ and $\operatorname{AMF}(p=0.339)$.

At the end of Ramadan, there was a statistically significant decrease of Doppler indices and AFI. However, all values were within the clinically accepted range. All the changes can be attributed to lapse of one month duration.

\section{DISCUSSION}

This study demonstrated that in young healthy pregnant women, fasting for a whole month during Ramadan had no deleterious effect on fetal condition as evidenced by normal umbilical artery and middle cerebral artery Doppler indices and amniotic fluid index. These indices showed a statistically significant, but clinically insignificant, decrease at the end of the month. This decrease is fairly explained by the lapse of a whole month during the third trimester.

Fasting during Ramadan is an essential pillar of Islam, despite the fear of unknown risk of fasting during pregnancy, a large proportion of women prefer to fast. Nearly $2 / 3$ of the current series chose to fast. A comparable proportion $(67 \%)$ was reported in Singapore ${ }^{[15]}$. Higher rates were reported in a study in Pakistan $(88 \%)^{[16]}$; women believed that fasting in good health is an essential obligation in Islam. Likewise high rates were reported in other studies ${ }^{[17-19]}$. A study in the USA found higher proportion of fasting among immigrant women compared to those born in the USA. This stressed the impact of solid religious beliefs in Muslim countries ${ }^{[20]}$.

Several studies have discussed the impact of Ramadan fasting on pregnancy, mostly from the aspect of metabolic and hormonal effects. The current study concentrated on the possible dehydrating effect of fasting though Doppler study and amniotic fluid volume. Dehydration may compromise uteroplacental blood flow necessary for fetal growth and wellbeing ${ }^{[2]}$. It has been linked to perinatal death, fetal malformations, preterm birth, low birth weight and poor health at birth $^{[22,23]}$.

A previous Egyptian study of 110 healthy women in the third trimester of a singleton pregnancy reported similar results to the current study. Authors reported no effect of fasting for 10-12 hours on uterine, umbilical, and middle cerebral artery Doppler indices ${ }^{[24]}$.

Another study of 52 healthy pregnant women in Iran assessed amniotic fluid index and Doppler indices of uterine and umbilical arteries in two groups; fasting and non-fasting. Amniotic fluid index was similar in two groups with no significant difference in Doppler indices of uterine and umbilical arteries ${ }^{[25]}$. Similar findings were reported by other investigators ${ }^{[26,27]}$. Mirghani et al showed no significant effect of Ramadan fasting in uterine artery Doppler velocitometry ${ }^{[28]}$.

During daylight, women are liable to acute dehydration; however it seems that the whole month does not induce chronic hypohydration [leiper] which could explain the absence of effect on amniotic fluid volume and Doppler indices $^{[29]}$.

Other studies reported controversial findings about the effects of fasting during Ramadan in the mother and her fetus. Some investigators do not report any significant adverse effects. Dikensoy et al. ${ }^{[27]}$ found significantly lower glucose level among fasting women; but they did not observe maternal ketonemia or ketonuria. They concluded that fasting during Ramadan did not adversely affect intrauterine fetal development or the fetal well-being.

A retrospective cohort study of neonates of 284 mothers with a history of Ramadan fasting during pregnancy did not found any significant effect of maternal fasting during Ramadan on the neonatal birth weight ${ }^{[30]}$. This study confirmed the results of a larger older study 
that revised the birth weights of 13,351 babies born at full term. There was an increase in the prevalence of low birth weights $(4.5 \%$ to $8 \%)$ among babies when Ramadan occurred during the second trimester, but this was not significant ${ }^{[31]}$.

A prospective cohort study found that risk of preterm delivery was increased by fasting during Ramadan regardless of the gestational age during which fasting is observed $^{[32]}$. Although the relative risk of low weight birth was 1.5 times in mothers on fasting during first trimester, generally fasting did not seem to have inappropriate effect on intrauterine growth and birth-time indices. However, these are the findings in healthy women with appropriate nutrition $^{[33]}$.

Meanwhile, reported undesirable effects include increased risk of hyperemesis gravidarum ${ }^{[34]}$, and urinary tract infections; possibly owing to decreased fluid intake during fasting ${ }^{[35]}$. Other studies reported reduction in fetal breathing movements due to rather low levels of maternal blood glucose ${ }^{[36]}$ and reduction in the fetal biophysical profiles $^{[37]}$.

A more recent study suggested that fasting during Ramadan may have some effects that appear when the offspring gets older. These effects include poorer general health, higher hazard of developing symptoms indicative for serious disease as coronary heart disease and type 2 diabetes $^{[38]}$.

\section{CONCLUSION}

We can conclude that maternal fasting during Ramadan does not adversely affect fetal condition based on the finding of normal Doppler indices and amniotic fluid index, provided the woman is young and healthy. Women can be counseled to observe Ramadan fasting as long as they have no medical disorder compromising pregnancy. They can use the right for temporary exemption from fasting, if they hardly endure fasting.

\section{CONFLICT OF INTEREST}

There are no conflicts of interst.

\section{REFERENCES}

1. Robinson T, Raisler J. "Each one is a doctor for herself": Ramadan fasting among pregnant Muslim women in the United States. Ethn Dis. 2005;15(1 Suppl 1): S1-99-103.

2. Malhotra A, Scott PH, Scott J, Gee H, Wharton BA. Metabolic changes in Asian Muslim pregnant mothers observing the Ramadan fast in Britain. $\mathrm{Br}$ J Nutr 1989;61(3): 663-712.
3. Prentice AM, Prentice A, Lamb WH, Lunn PG, Austin S. Metabolic consequences of fasting during Ramadan in pregnant and lactating women. Hum Nutr Clin Nutr 1983;37(4): 283-94.

4. Gin H, Vambergue A, Vasseur C et al. Blood ketone monitoring: A comparison between gestational diabetes and nondiabetic pregnant women. Blood ketone monitoring: A comparison between gestational diabetes and non-diabetic pregnant women. Diabetes Metab 2006; 32: 592-7.

5. Sosa C, Abecia JA, Carriquiry M, Forcada F, Martin GB, Palacín I, et al. Early pregnancy alters the metabolic responses to restricted nutrition in sheep. Domest Anim Endocrinol 2009; 36(1): 13-23.

6. Wauters M, Considine RV, Van Gaal LF. Human leptin: from an adipocyte hormone to an endocrine mediator. Eur J Endocrinol 2000;143(3): 293-311.

7. Kobayashi Y, Boyd CK, Bracken CJ, Lamberson WR, Keisler DH, Lucy MC. Reduced growth hormone receptor (GHR) messenger ribonucleic acid in liver of periparturient cattle is caused by a specific down-regulation of GHR 1A that is associated with decreased insulin-like growth factor I. Endocrinology 1999;140(9): 3947-54.

8. Brecchia G, Menchetti L, Cardinali R, Polisca A, Troisi A, Maranesi M, Boiti C. Effects of fasting during pregnancy in rabbit does. Proceedings 10th World Rabbit Congress, September 2012, Egypt, 341-345.

9. Kaplan M, Eidelman AI, AboulaWa Y. Fasting and the precipitation of labor: the Yom Kippur eVect. JAMA 1983; 250: 1317-8

10. Cross JH, Emerson J, Wharton BA. Ramadan and birth weight at full term in Asian Moslem pregnant women in Birmingham. Arch DisChild 1990;65: 1053-6

11. Hefni M, Fikry SAH, Abdalazim M, Abdelkhalik MA. Fasting in Ramadan and preterm labour. Saudi Med J. 1993;14: 130-2

12. Joosoph J, Abu J, Yu SL. A survey of fasting during pregnancy. Singapore Med J. 2004;45(12): 583-6.

13. Mubeen SM, Mansoor S, Hussain A, Qadir S. Perceptions and practices of fasting in Ramadan during pregnancy in Pakistan. Iran $J$ Nurs Midwifery Res. 2012;17(7): 467-71.

14. Phelan JP, AhnMO, Smith CV, et al. Amniotic fluid index measurements during pregnancy. J Reprod Med. 1987;32: 601-4. 
15. Joosoph J, Abu J, Yu SL. A survey of fasting during pregnancy. Singapore Med J. 2004;45: 583-6.

16. Mubeen SM, Mansoor S, Hussain A, Qadir S. Perceptions and practices of fasting in Ramadan during pregnancy in Pakistan. Iran $\mathbf{J}$ Nurs Midwifery Res. 2012;17(7): 467-71.

17. Kavehmanesh Z, Abolghasemi H. Maternal Ramadan fasting and neonatal health. J Perinatol. 2004; 24: 748-50.

18. Pearce A, Mayho P. Provision of antenatal care during Ramadan. Br J Midwifery. 2004;12: 750-2.

19. Pathy R, Mills KE, Gazeley S, Ridgley A, Kiran T. Health is a spiritual thing: Perspectives of health care professionals and female Somali and Bangladeshi women on the health impacts of fasting during Ramadan. Ethn Health. 2011;16: 43-56. [PubMed]

20. Robinson T, Raisler J. "Each one is a doctor for herself": Ramadan fasting among pregnant Muslim women in the United States. Ethn Dis. 2005;15: S1-99-103.

21. Osol G, Mandala M. Maternal uterine vascular remodeling during pregnancy. Physiology (Bethesda). 2009;24: 58-71.

22. Brace R. Physiology of amniotic fluid volume regulation. Clin Obstet Gynecol. 1997;40(2): 280-9.

23. Casey BM, McIntire DD, Bloom SL, Lucas MJ, Santos R, Twickler DM, Ramus RM, Leveno KJ. Pregnancy outcomes after antepartum diagnosis of oligohydramnios at or beyond 34 weeks' gestation. Am J Obstet Gynecol. 2000;182(4): 909-12..

24. Abd-El-Aal DE, Shahin AY, Hamed HO. Effect of short-term maternal fasting in the third trimester on uterine, umbilical, and fetal middle cerebral artery Doppler indices. Int J Gynaecol Obstet. 2009;107(1): 23-5.

25. Moradi M. The effect of Ramadan fasting on fetal growth and Doppler indices of pregnancy. J Res Med Sci. 2011;16(2): 165-9.

26. Kamyabi Z, Naderi T. The effect of Ramadan fasting on amniotic fluid volume. Saudi Med J. 2004;25(1): 45-6.

27. Dikensoy E, Balat O, Cebesoy B, Ozkur A, Cicek
H, Can G. Effect of fasting during Ramadan on fetal development and maternal health. J Obstet Gynaecol Res. 2008; 34(4): 494-8.

28. Mirghani HM, Salem M, Weerasinghe SD. Effect of maternal fasting on uterine arterial blood flow. J Obstet Gynaecol Res. 2007;33(2): 151-4.

29. Leiper JB, Molla AM, Molla AM. Review Effects on health of fluid restriction during fasting in Ramadan. Eur J Clin Nutr. 2003; 57 Suppl 2: S30-8.

30. Kavehmanesh Z, Abolghasemi H. Maternal Ramadan fasting and neonatal health. J Perinatol. 2004;24(12): 748-50.

31. Cross JH, Eminson J, Wharton BA. Ramadan and birth weight at full term in Asian Moslem pregnant women in Birmingham. Arch Dis Child. 1990; 65(10 Spec No): 1053-6.

32. Awwad J, Usta IM, Succar J, Musallam KM, Ghazeeri G, Nassar AH. The effect of maternal fasting during Ramadan on preterm delivery: a prospective cohort study. BJOG. 2012; 119(11): 1379-86.

33. Ziaee V, Kihanidoost Z, Younesian M, Akhavirad MB, Bateni F, Kazemianfar Z, Hantoushzadeh $S$. The effect of ramadan fasting on outcome of pregnancy. Iran J Pediatr. 2010; 20(2): 181-6.

34. Rabinerson D, Dicker B, Kaplan A, Ben-Rafael Z, Dekel A. Hyperemesis gravidarum during pregnancy. J Psychosom Obstet Gynaecol. 2000;21:189-1.

35. Bandyopadhyay S, Thakur JS, Ray P, Kumar R. High prevalence of bacteriuria in pregnancy and its screening methods in north India. J Indian Med Assoc. 2005;103: 259-62.

36. Mirghani HH, Weerasinghe DS, Smith JR, Ezimokhai M. The effect of intermittent maternal fasting on human fetal breathing movements. J Obstet Gynaecol. 2004;24: 635-7.

37. Mirghani HM, Weerasinghe DS, Ezimokhai M, Smith JR. The effect of maternal fasting on the fetal biophysical profile. Int J Gynaecol Obstet. 2003;81: 17-21.

38. van Ewijk R. Long-term health effects on the next generation of Ramadan fasting during pregnancy. J Health Econ. 2011;30(6): 1246-60. 